\title{
Real-time Fluorescence Quantitative PCR and Prediction of Bovine Trf 2 Protein Funtion
}

\author{
Ya-Hong $\mathrm{HUAI}^{1 *}$ and Shang-Zhong $\mathrm{XU}^{2}$ \\ ${ }^{1}$ Zhongshan Torch Polytechnic, Guangdong, 528436, China \\ ${ }^{2}$ Institute of animal science, Chinese academy of agriculture science, Beijing, 100094, \\ China \\ *hyh7810@163.com
}

Keywords: Trf2 gene, cDNA cloning, Real-time fluorescence quantitative PCR, Bioinformation prediction.

\begin{abstract}
In order to study $\operatorname{Trf} 2$ protein function in the sperm production, the $\operatorname{Trf} 2$ gene was studied and the protein function was predicted in this paper. Based on blast searches with the mRNA sequence of human Trf 2 and the bovine-EST databases, we used fragment assembly and RT-PCR technology to amplify sequence. The results show that a 1701 bp cDNA fragment (GenBank accession No.EU140625) is first obtained. The sequence contains a 561 bp ORF encoding 186 amino acids. Homology analysis show that the amino acid sequences of bovine Trf 2 is highly homologous to other species. Real-time F Q- PCR demonstrates that the level of Trf 2 gene in liver and testis is highest in all organizations, relative to muscle. The protein may be associated with spermatogenesis. We acquire the Trf2 gene sequences and predict the function of Trf2 protein.
\end{abstract}

\section{Introduction}

The TBP related factor 2(Trf 2) is a mammal testicular tissue highly express gene which is belongs to the TBP class factor [1,2,3]. It plays a role as a transcriptional regulatory factor. It has been demonstrated that if the gene is lacking, the gene mutation and the sperm cells development are blocked, and cell apoptosis is serious [4]. In the process of spermatogenesis, The TBP as a member of the transcription factor combines with TATA - box specificity to activate these gene transcriptions [5]. The transcription of these genes, which have no TATA sequence in the promoter region, is dependent on the TBP similarity factor (TLF), also known as the TBP related factor 2 (TBF2). It has been showed that the level of TLF gene in testis is higher relative to other organizations. If the TLF is lacking, which will cause increased significantly number of haploid sperm cells apoptosis, abnormal acrosome, heterochromatin center faults and abnormal testicular specific gene expression, and eventually cause infertility[6,7]in mice. The research of the gene and protein has not reported at present. Trf2 gene cDNA sequence, and fluorescent quantitative analysis were studied, at the same time, Trf 2 protein function be predicted. It will provide theoretical and practical basis for the following molecular functions and marker-assisted selection research. It will provide theoretical and practical basis for the following molecular functions and marker-assisted selection research. 


\section{Materials and Methods}

\section{The Extraction of Total RNA and RT-PCR}

Twelve cattle of Simmental(Male and female half ), which were feeding about 9 months, were slaughtered (Shengyang, China), and then some tissue were taken using operating knife blade which was treated by $75 \%$ alcohol, packed, labeled and kept in liquid nitrogen.

Total RNA was extracted from testis and other tissues weighing about 100mg using Trizol reagent (Gibco BRL Co.Ltd., USA), respectively. $1 \mu \mathrm{L}$ Total RNA was run in $0.7 \%$ agrose gel electrophoresis to detect its integrity. RNA density was determined using Spectrophotometer. A260/A280 value was at 1.7-1.9.

First strand cDNA was synthesized using reverse transcriptase. The total volume was $50 \mu \mathrm{L}$ : total RNA $1 \mu \mathrm{L}$, Oligo dT18(14 nmoL/ $\mu \mathrm{L}) 5 \mu \mathrm{L}$, M-MLV $(200 \mathrm{U} / \mu \mathrm{L})$ reverse transcriptase $1 \mu \mathrm{L}, \mathrm{RNA}$ enzyme inhibitor $1 \mu \mathrm{L}$,dNTP $\operatorname{Mix}(10 \mathrm{mmol} / \mathrm{L}) 6.25 \mu \mathrm{L}, 5 \times \mathrm{RT}$ Buffer $10 \mu \mathrm{L}$ RNase free water $25.75 \mu \mathrm{L}$ (TaKaRa Biotechnology Co., Ltd. Dalian, China). The reverse transcriptase of mRNA was run as follows: $70^{\circ} \mathrm{C} 5 \mathrm{~min}, 37^{\circ} \mathrm{C} 1 \mathrm{~h}$, $95^{\circ} \mathrm{C} 5 \mathrm{~min}$.

$1 \mu \mathrm{L}$ cDNA was used for PCR reaction. The PCR was run as follows: initial incubation at $94{ }^{\circ} \mathrm{C}$ for $90 \mathrm{~s}$, followed by 40 cycles $\left(94{ }^{\circ} \mathrm{C} 30 \mathrm{~s} ; 53.7{ }^{\circ} \mathrm{C} / 48.2^{\circ} \mathrm{C} 30 \mathrm{~s}, 72{ }^{\circ} \mathrm{C}\right.$ $60 \mathrm{~s}$ ) , and a final extension of $10 \mathrm{~min}$ at $72^{\circ} \mathrm{C}$. Product of PCR was screened with $1.5 \%$ agarose gel electrophoresis.

\section{Trf 2 Gene cDNA Cloning}

RNA sequence of the human Trf2 was obtained from NCBI (GenBank accession number AF136570), and was used to search for bovine expressed sequence tags (ESTs) in the EST-others database through standard BLAST (http://www.ncbi.nlm.nih.gov/blast/).One hundred bovine expressing sequence tags (ESTs) were assembled into one contig. The contig was carried out EST splicing, blasted with genome of cattle. The bovine ESTs that have more than $80 \%$ similarity with the corresponding human mRNA were used for primer design with Primer Premier 5.0 (Premier Biosoft International, Palo Alto, CA, USA) by means of splicing sequence and were synthesis by SinoGenoMax (SinoGenoMax Co., Ltd. Beijing, China). The primer sequences and the corresponding regions binding regions are shown in Table 1.

The products were purified with PCR Purification System (Beijing TIANGEN Co.Ltd. Beijing, China) and cloned into the PMD19-Vector (TaKaRa Biotechnology Co., Ltd. Dalian, China).Products which was the single fragments were transformed into DH5 $\alpha$ sensitive cell, spreading ampicillin, X-Gal and IPTG and incubated 12 16 h. White colony was packed in eppdorff tube filling with $1.5 \mathrm{~mL} \mathrm{LB}$ medium, shaked $3 \mathrm{~h}$ in air vibration balneum (HZQ-C, Harbin, China). $1 \mu \mathrm{L}$ bacterium liquid was used for PCR. One single product was sequenced (SinoGenoMax Co., Ltd. Beijing, China).

\section{Real-time Fluorescence Quantitative PCR}

According to the FQ-PCR test requirements, the template concentration and PCR reaction cycle number and other experimental condition is optimized. $\beta$-actin gene was used to internal genes in fluorescence quantitative PCR experiments, primers were designed according to $\beta$-actin gene (Accession number AY141970) template sequence. Primers sequences of $\beta$-actin and Trf 2 gene were designed containing part of the introns, in order to prevent DNA pollution affects the experimental results. Fluorescence quantitative primer sequences and annealing temperature are shown in 
Table 1. PCR products were detected with $1.5 \%$ agarose gel, then it was take pictures with Gel imaging system. Trf 2 gene product ratio of each tissue was calculated by quantity one software program in fluorescence quantitative analysis.

\section{Sequence Analysis and Function Prediction}

Trf 2 gene sequences were analyzed about amino acid composition and isoelectric point analysis using DNAMAN and DNAstar software. Protein structure domain was predicted using on-line tool (http://smart.embl-heidelberg.de/).

Table 1 Primers used for cloning, real-time Fluorescence Quantitative PCR

\begin{tabular}{|c|c|c|c|c|}
\hline Fuction & $\begin{array}{l}\text { Gene } \\
\text { symbols }\end{array}$ & Primer Sequence $\left(5^{\prime}-3^{\prime}\right)$ & $\begin{array}{l}\text { Length of } \\
\text { fragment }\end{array}$ & $\begin{array}{l}\text { Annealing } \\
\text { temperature }\end{array}$ \\
\hline & & & $/ \mathrm{bp}$ & ${ }^{\circ} \mathrm{C}$ \\
\hline Cloning & $\mathrm{T}-1$ & F:5' CAACAAAGCACGAAAGACGG 3' & 731 & 53.7 \\
\hline \multirow[t]{4}{*}{ PCR } & & R: 5' AGCCTTTACATTGGGTCCTG 3' & & \\
\hline & $\mathrm{T}-2$ & F: 5' GTTTGAAATCCGTTTGCCAG 3' & 1137 & 48.2 \\
\hline & & R: 5' AACCAGAGTTGAGTCTTTCC 3' & & \\
\hline & Tbd & F: 5' CTTCTTCACTTGTTGCTCCA 3' & 238 & 57.0 \\
\hline FQ- & & R: 5' TAAACTACCCCAATGGATGC 3' & & \\
\hline \multirow[t]{2}{*}{ PCR } & $\beta$-actin & F: 5'GAAGTGTGACGTCGACATCCG 3' & 282 & 55.0 \\
\hline & & R: 5' GCCTAGAAGCATTTGCGGTG 3' & & \\
\hline
\end{tabular}

\section{Results and Discussion}

cDNA Sequence Acquisition and Sequence Analysis. Fig.1 shows that fragments of $731 \mathrm{bp}$ and $1137 \mathrm{bp}$ were, respectively, amplified with primers T-1 and T-2. The two fragments constituted the bovine Trf 2 mRNA sequence. The sequences were then compared to both the original bovine EST and the corresponding human gene sequences, confirming that the PCR fragments were amplified from the expected bovine Trf2 gene. The sequence had been submitted to GenBank (Accession number EU140625). It is composed of 1701 bp nucleotides and has a 561 bp ORF (Open Read Frame) ecoding a protein of 186 amino acids. 907 bp nucleotides were contained in 5 'untranslated region, 233 bp nucleotides was contained in 3' untranslation regions. A GenBank database search using DNAMAN software revealed that the bovine Trf2 mRNA sequence exhibits identity with shshawksa (37.7\%), human (36.9\%), mouse $(36.7 \%)$.

\section{Fluorescence Quantitative Expression Spectrum Analysis}

Verification of Primers. $1 \mu \mathrm{L}$ cDNA was used for PCR reaction. The total volume was $25 \mu \mathrm{L}$ : cDNA $1 \mu \mathrm{L}, 2$ x qPCR TaqMix $12.5 \mu \mathrm{L}$ (don't contain dye), each forward and reverse primers $0.5 \mathrm{~mL}$ (Using the Tbd and $\beta$-actin primers in Table 1). RNase free water $10.5 \mu \mathrm{L}$. Reaction program was run as follows: $95^{\circ} \mathrm{C} 5 \mathrm{~min}$, followed by 40 cycles $\left(95^{\circ} \mathrm{C} 15 \mathrm{~s} \rightarrow 65^{\circ} \mathrm{C} 35 \mathrm{~s}\right)$ using SLAN fluorescence quantitative PCR. 
Simmental Tissue Expression Profile. cDNA first chain was synthesized using reverse transcriptase from different tissue. Then $1 \mu \mathrm{L}$ cDNA was used for PCR reaction. Product of PCR was screened with 1.5\% agarose gel electrophoresis. Amplification bands were detected in each tissue in line with expectations. The gene expression abundance relative to the muscle tissue was analyzed using the real-time fluorescence quantitative analysis. The result is shown in Fig.2.The results show that highest Trf 2 gene mRNA level in testis and liver in the experiment of 12 tissues, the lowest Trf 2 gene mRNA level in the stomach and spleen. The results of tissue expression profile and fluorescence quantitative PCR showed that gene Trf2 expressed and bovine in the tissue expression, which was consistent with the Rabenstein ${ }^{[8]}$ conclusion. Compared with muscle tissue, Trf 2 expression amount were higher in the testis and liver, and lower in the stomach and spleen.

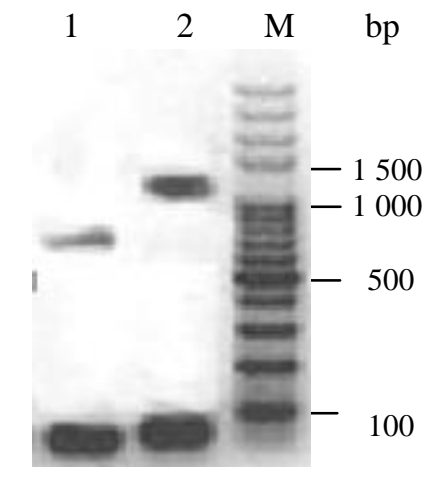

Fig. 1 Electrophoresis of Trf 2 gene PCR product

\section{Bioinformatics Analysis of Amino Acid Sequence}

Trf 2 gene nucleotide encodes 186 amino acids. Using DNAMAN software analyzed the result was showed that molecular weight of Trf 2 protein was $20.8 \mathrm{KDa}$ and pI was 9.61. Polar amino acid(N,C,Q,S,T,Y)had 44, accounting for $23.8 \%$. Hydrophobic amino acids had (A, I, L, F, W, V) had 75, accounting for 40.5\%.Using on-line tools (http://smart.embl-heidelberg.de/), Trf 2 proteins were found to contain two across a membrane structure domain(TLF and SPT15). Using DNAMAN software, amino acids sequence was compare cattle trf 2 with other species. It was found that 143 AA amino acid sequence more than other species in the front in mice and the back more than 34 $\mathrm{AA}$, and there are $20 \mathrm{AA}$, which do not match the other species amino acid sequence. It had a high degree of consistency compare cattle Trf2 protein amino acid sequence with people, kangaroo, mice, dogs.

Bioinformatics analysis results and FQ-PCR conclusion predict that the protein may be related with the formation of cattle sperms, which could lay an important foundation for the further study of the protein function. Trf2 is a unique factor of multicellular and it had $40 \%$ similarity with TBP $[9,10,11,12,13]$. We can confer that Trf 2 may play a role in improving transcriptional regulation of core promoter. The rat Trf 2 has no effect on embryonic development but for spermatogenesis is the necessary $[14,15,16]$ 


\section{Conclusions}

The cDNA sequence of Trf2 gene is obtained and submited GenBank((GenBank accession No.EU140625)); Trf2 protein function is predicted using bioinformatics software and FQ-PCR technology.

\section{Acknowledgement}

This research was financially supported by National Programs for High Technology Research and Development.

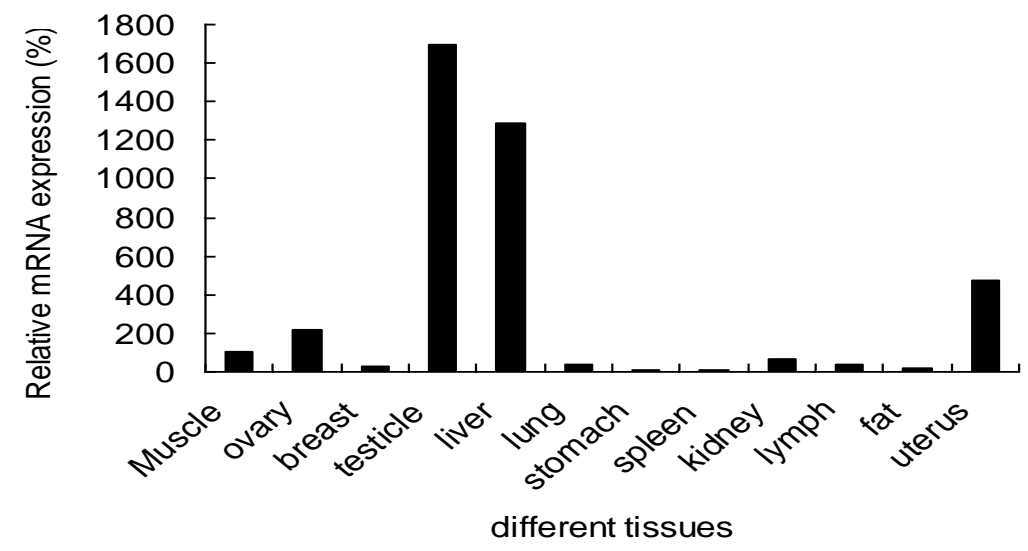

Fig.2 Trf2 gene mRNA relative expression levels in 12 tissues using real-time fluorescent quantitative PCR

\section{References}

[1] T. E. Crowley, T. Hoey, J. K. Liu, Jan, Nature.361(1993) 557-561.

[2] A.Hochheimer, S. Zhou,S.Zheng, Nature .420 (2002)439-445 .

[3] S.P.Persengiev, X.Zhu, B.L.Dixit, Proc,Natl.Acad.Sci. 100(2003)14887-14891.

[4] J.C.Dantonel, J. M.Wurtz, O.Poch, Trends Biochem. Sci. 24(1999)335-339.

[5] S. Kimmins, N. Kotaja, I.Davidson, Rep rod. 128(2004) 5-12.

[6] D. Zhang, T.L .Penttila, P.L .Morris, Science, 292(2001) 1153-1155.

[7] I. Martianov,G.M Fimia, A. Dierich, Mol Cell, 7,(2001)509-515.

[8] M.D. Rabenstein, S. Zhou, J. T. Lis, Proc. Natl. Acad. Sci. USA, 96(1999) 4 791-4 796.

[9] J. C. Dantonel, S.Quintin, L. Lakatos, and L. Tora, Mol. Cell. 6(2000)715-722.

[10] L.Kaltenbach, M.A.Horner, J.H.Rothman, and S.E.Mango, Mol. Cell.6 (2000)705-713.

[11] T. Ohbayashi, T. Kishimoto, Y. Makino and M. Shimada, Biochem. Biophys. Res. Commun.255 (1999b) 137-142.

[12] M.Shimada, T.Ohbayashi, M. Ishida, T. Nakadai, Nucleic Acids Res. 27,(1999)3146-3152.

[13] G. J.Veenstra, D. L.Weeks, A. P. Wolffe, Science 290(2000)2312-2315. 
[14] I.Martianov, G. M. Fimia, A. Dierich, and M. Parvinen, Mol. Cell 7(2001)509-515.

[15] I.Martianov, S. Brancorsini, A. Gansmuller, Development 129(2002)945-955.

[16] T. Matsumoto, I. Turesson, M. Book, Cell Biol.156(2002)149-160. 